\title{
A STUDY OF DRUG USE IN FIVE URBAN CENTRES IN KENYA
}

\section{David M. Ndetei ${ }^{* 1}$ Lincoln Khasakhala ${ }^{1}$ Francisca A. Ong'echa ${ }^{2}$ Donald Kokonya $^{3}$ Victoria Mutiso ${ }^{4}$ Mary Kuria $^{1}$ Gideon Odhiambo ${ }^{5}$ Solomon Akanga ${ }^{5}$}

\author{
${ }^{1}$ University of Nairobi and Africa Mental Health Foundation (AMHF); \\ ${ }^{2}$ Coast Provincial General Hospital \& AMHF; \\ ${ }^{3}$ Kakamega Provincial General Hospital \& AMHF; \\ ${ }^{4}$ Africa Mental Health Foundation (AMHF); \\ ${ }^{5}$ University of Nairobi
}

\begin{abstract}
Few studies have addressed the reasons for substance use in Kenya, with most focusing on prevalence rates in school-based and general population samples. None have been carried out among people already using drugs. This study, based on five samples of drug users, aimed to identify patterns of, factors contributing to and consequences of substance use; compare socio-demographic characteristics; document help-seeking behaviours of substance abusers as well as their family and social dynamics. Active or former substance abusers $(\mathrm{N}=1,420)$ were interviewed using a structured questionnaire format. The peak age for substance abuse was between 21 and 30 years and most abusers were male. Leisure, stress and peer pressure were the most common reasons given for abusing substances. There were negative economic and work-related impacts of abusing substances. Risky sexual behaviour may have been a consequence of abusing substances. Substance abusers need assistance as most of them could benefit from programmes for treatment and rehabilitation.
\end{abstract}

KEY WoRDS: substance abuse, Kenya, urban, peri-urban

\section{INTRODUCTION}

In 1999, out of 134 countries in which drug injecting had been confirmed, 114 reported a relationship between substance abuse and human immuno-deficiency virus/acquired immune deficiency syndrome (HIV/AIDS) (Joint United Nations Programme on HIV/ AIDS [UNAIDS], 1999). In 1995, it was estimated that $5-10 \%$ of all HIV/AIDS cases worldwide were due to the use and sharing of contaminated needles and syringes to inject drugs of abuse (Weekly Epidemiological Record, 1995). A multi-centre seroprevalence study at needle exchange sites in Canada found an overall HIV prevalence rate of $6.9 \%$ among intravenous drug users (IDUs). Needle sharing occurred among $36 \%-46 \%$ of the participants (Alary, 1999; Health Canada, 1997). Followup studies showed a 2-3\% increase in HIV

\footnotetext{
* Correspondence concerning this article should be addressed to: David M. Ndetei, Professor of Psychiatry, University of Nairobi, \& Director, Africa Mental Health Foundation (AMHF), P. O. Box 48423, 00100-GPO, Nairobi, Kenya. E-mail: dmndetei@mentalhealthafrica.com ordmndetei@uonbi.ac.ke
} 
incidence (Tannenbaum, 1999; Lamothe, 1999; Wallace, 1999; Millson, Myers, Calzavara, Major, Fearon, Rea, \& Wallace, 2000; Patrick, Schechter Strathdee, Cornelisse, Rekart, Cook, Montaner, \& O'Shaughnessy, 1998; Tyndall, 1999; Archibald, Remis, Farley, \& Sutherland, 1998; Health Canada, 2000).

New HIV cases among IDUs in the United States increased in 2000 (United Nations Office for Drug Control and Crime Prevention [UNODCP], 2000) and those who injected drugs, together with their sex partners, represented about one-third of all those who had been infected with HIV since 1981 (www.HIVdent.org). For these populations, programme strategies emphasised preventing drug abuse, treating drug abusers and decreasing needle sharing (Centres for Disease Control and Prevention [CDC], 1998a, 1998b). In Kenya, Ndetei, Kathuku, \& Othieno (1997) found a wide range of drugs of abuse including narcotics, being used in combination, but none was being used intravenously. They established that the most vulnerable group was in the 16-20-year age range.

There have been five school surveys that specifically addressed drug use and abuse in Kenya (Dhadphale, Mengech, Syme, \& Acuda, 1982; Yambo, \& Acuda, 1983; Kuria, 1996; Ndetei et al., 1997; The National Agency for the Campaign Against Drug Abuse [NACADA], 2004). Two of the earliest school surveys on drug abuse found that secondary school students in Kenya rarely used opiates and cocaine (Dhadphale et al., 1982; Yambo \& Acuda, 1983) and that cannabis and khat (a psycho stimulant) were the major illicit drugs used. Yambo and Acuda's study (1983) sampled from both rural and urban populations while Dhadphale et al. (1982) noted that illicit use of social drugs (alcohol, tobacco) and inhalants among Kenyan secondary school students was an urban/peri-urban problem.

In a Rapid Situational Assessment (RSA) of the linkages between illicit drug use and HIV/AIDS, Ndetei's (2004) study included various stakeholders, and used both primary and secondary data with a view to finding intervention entry points. . Age of first drug use was reported in the range of 0-9 years, starting with volatile hydrocarbons. The incidence of drug use increased within the 10-15-year age group and apart from volatile hydrocarbons $(40 \%)$, cannabis $(31.4 \%)$ was also being used. Use of cocaine (11.4\%), mandrax, amphetamines and heroin also began at this age. Those who initiated drug use at 16-20 years chose cannabis, mandrax and amphetamines. None of the previous studies reported intravenous drug use in schools, although in 1997, Ndetei et al (1997) recommended that it should be the subject of a study. The authors noted the following as important factors associated with drug abuse and suggested possible intervention entry points: (i) Biological factors - a biological basis for dependence; (ii) Psychological factors; and (iii) Social/environmental factors.

The NACADA in Kenya (2004) reported the findings of a national survey on drug use (data collected in 2001/2002), including tobacco and alcohol use. In the survey, only information on schooling was collected and the youth (10 -24 years) were grouped into those who were attending school and those who were not. The study reported data on lifetime and current (within the last 30 days) use of only five drugs alcohol, tobacco, bhang (cannabis), miraa (khat) and inhalants - for each of the eight provinces of Kenya. However, without information on the numbers studied, it is not possible to evaluate whether or not the variations between the provinces were significant or, if they were mere trends or simply artefacts.

This study aimed to fill the gaps left by the NACADA study. It also aimed to build on Ndetei et al.'s (1997) study by providing scientific evidence for policies on possible entry points for intervention, while at the same time replicating epidemiological surveillance data to monitor changing and emerging trends. This is in conformity with emerging global trends that drug abuse even in youth is comorbid with certain psychological and social pathologies (Smart, Hughes, \& Johnson, et al., 1980; Boys, Farrell, \& Taylor, et al., 2003). This study assessed differences in patterns of drug use in five urban centres of Kenya, and 
the association between injecting drug use and positive HIV status.

\section{METHOD}

This was a descriptive cross-sectional study of substance users $(\mathrm{N}=1,420)$ in five major urban and commercial centres in Kenya, namely Mombasa $(\mathrm{n}=350)$, Malindi $(\mathrm{n}=$ 183), Nairobi $(\mathrm{n}=364)$, Nakuru $(\mathrm{n}=264)$ and Kisumu $(\mathrm{n}=277)$. The study centres were cosmopolitan and had good transport linkages both within and outside Kenya. Nairobi is the capital city located in the central part of the country; Mombasa is a port city on the Indian Ocean and Kisumu is the largest city in the western part of Kenya. Nakuru is located in a largely farming area within the Great Rift Valley. Malindi is a coastal resort situated about 170 kilometres north of Mombasa. All these centres apart from Malindi, are on the major transport route from the coast to Central Africa. Urban centres were chosen because worldwide findings have reported that the highest levels of substance use and abuse were found in major urban centres (Patrick et al., 1998; UNODCP, 2000).

The study population included active and former substance abusers who were recruited from rehabilitation and treatment centres, streets, hospitals and in substance abuse dens within the geographical study areas. Data collection in all the centres was carried out over a twelve-week period between September and December 2003. The sampling procedure included purposive, quota and open-street sampling as well as snowballing. Field guides assisted in recruitment. Structured, semistructured and open-ended questionnaires were used in face-to-face (one on one) interviews. The information elicited included sociodemographic data, drug use patterns, sexual practices, patterns of intravenous drug use and related behaviour and socio-economic support systems.

\section{RESULTS}

The results are summarised in table and narrative format. There were 14 substances of abuse recorded: alcohol, nicotine, cannabis, Catha edulis, cocaine, heroin, sedatives, pethidine, kuber, morphine, inhalants such as glue, phencyclidine, pills like piriton and amphetamines. Regional comparisons revealed that alcohol abuse was reported with the highest frequency (54.5\%) in Kisumu with the lowest prevalence being reported in Malindi (6.6\%). Alcohol (36.3\%) and cocaine $(2.2 \%)$ were the most and least frequently abused drugs nationally.

The major reasons reported for taking drugs included leisure, stress (defined as a state of mental or emotional strain or suspense that caused worry or emotional tension), peer pressure, accidental and addiction. In all regions except in Malindi, leisure was given as the most important reason for taking drugs. Stress was the second most important reason for taking drugs except in Nakuru and Kisumu. Accidental taking of drugs was reported at minimal levels.

Table 1. Concerns raised by relatives/friends of drug users in different regions (\%)

\begin{tabular}{lccccc}
\hline \multicolumn{1}{c}{ Problem areas } & Mombasa & Malindi & Nairobi & Nakuru & Kisumu \\
\hline Medical health & 6.93 & 8.6 & 16.9 & 4.1 & 18.0 \\
Marital & 1.5 & 8.7 & 11.0 & 1.3 & 15.9 \\
Other family & 8.2 & 4.7 & 7.3 & 7.5 & 5.4 \\
issues & 1.5 & 1.0 & 1.0 & 1.8 & 0.5 \\
Financial & 1.0 & 1.1 & 4.4 & 1.2 & 4.3 \\
Work-related & 1.9 & 1.2 & 1.7 & 0.5 & 1.0 \\
Legal & 2.7 & 0.7 & 2.5 & 1.0 & 3.7 \\
Social & 14.0 & 2.6 & 4.7 & 9.8 & 1.5 \\
Others & & & & &
\end{tabular}


When asked who else in the family was abusing drugs, the most commonly mentioned members were brothers and fathers. In Nairobi, brothers as fellow drug users were reported with the highest frequency (39.6\%). Mothers (2.8\%) and sisters (3.8\%) were also reported to be drug users even though at very low frequencies.

Drug use affected the users' feelings towards other family members, friends and towards workmates/employment. Kisumu recorded the highest frequency of drug abusers who felt less caring towards their children (16.4\%) and spouses $(13.2 \%)$ and this was nearly twice as high as that reported for all centres combined (8.4\% and $7.2 \%$, respectively).

A wide range of concerns was raised by relatives and friends concerning the drug users' habits as shown in Table 1. These were related to health, family, finances, legal as well as social problems. Drug users suffered poorer health status and this may have led to them making repeated visits to hospitals or taking medication to treat their symptoms. This in turn may have affected family finances as money that was allocated to other uses was redirected to the treatment of drug users. Relationships within the family may also have been affected as drug use habits led to feelings of resentment among those family members who had to accommodate them. In terms of legal and social problems, drug users were more likely to get into trouble with law enforcement agencies as a result of their habits. Performance at work may also have been affected as drug users were not able to work at optimal levels. Relationships with community members may also have been affected as drug users were stigmatised as most people perhaps out of fear, did not want to be seen to associate with them.

More than half of the drug users in Mombasa $(53.1 \%)$ reported having lost a friend through death as a consequence of substance abuse and this was notably higher than the $32.7 \%$ average reported for all centres. The other centres reported frequencies ranging from $14.8 \%$ in Kisumu to $37.8 \%$ in Nakuru. Most of those who had died were fellow substance abusers or friends of the opposite sex.
On average, the most common source of money for the purchase of drugs reported by drug users was personal income (43.2\%). Other means of sourcing money for drugs included stealing, which was reported with the highest frequency in Nairobi (17.3\%), begging and borrowing. In Kisumu, $21.7 \%$ of the respondents reported gave gifts in exchange for money for drugs.

Less than one third of the drug users reported that they sought help in dealing with their drug problem. The highest and lowest frequency of those seeking help was recorded in Mombasa $(30.6 \%)$ and in Kisumu (9.4\%), respectively. Help was sought from family members, friends and counsellors or health workers. Parents were approached for help with the least frequency $(2.6 \%)$ while up to $13.6 \%$ of the drug abusers reported having sought help from counsellors or health workers. The overall mean age for the respondents was 29.2 years: in Nairobi, it was 27.9 years, Mombasa 28.5 years, Kisumu 33.8 Years, Nakuru 25.3 years and Malindi 31.9 years.

Drug users obtained referrals to treatment/ rehabilitation centres through family members, work colleagues and private professional and religious organisations as well as health facilities. Schools, social and correctional services also served as referral sources. Overall, family members and friends played a big role and in Kisumu, at least $14.1 \%$ of the drug users reported having used them as sources of referrals to treatment centres. The proportion of those who sought treatment for their drug habits across all the centres was however very low (37.4\%).

Table 2 illustrates intravenous drug use patterns. The lowest percentage of non-IDUs was reported in Nairobi (44\%) while the highest was reported in Malindi (89.6). Overall, $76.7 \%$ of all drug users were non-IDUs. Among those who were using drugs intravenously, the highest rates of daily needle use were reported in Mombasa and Malindi, while the lowest rates were reported in Kisumu. Sharing of needles was common despite the fact that majority of the drug users reported that they did not clean or bleach the needles after or before use. 
Table 2. Patterns of intravenous drug use in different regions (\%)

\begin{tabular}{|c|c|c|c|c|c|}
\hline Drug Use & $\begin{array}{c}\text { Mombasa } \\
(n=350)\end{array}$ & $\begin{array}{l}\text { Malindi } \\
(\mathrm{n}=183)\end{array}$ & $\begin{array}{l}\text { Nairobi } \\
(\mathrm{n}=364)\end{array}$ & $\begin{array}{l}\text { Nakuru } \\
(\mathrm{n}=\mathbf{2 4 6})\end{array}$ & $\begin{array}{c}\text { Kisumu } \\
(\mathrm{n}=\mathbf{2 7 7})\end{array}$ \\
\hline \multicolumn{6}{|l|}{ Annual prevalence rates of IDU } \\
\hline Once a week & 1.1 & 0.5 & 12.9 & 6.1 & 4.3 \\
\hline More than once a week & 1.7 & 9.3 & 34.9 & 3.3 & 11.2 \\
\hline Once a day & 2.9 & 0.5 & 4.4 & 2.0 & 0 \\
\hline More than once a day & 17.1 & 10.4 & 3.8 & 0.4 & 0 \\
\hline Injecting self/alone? Yes & 12.9 & 0.5 & 12.9 & 4.9 & 2.2 \\
\hline \multicolumn{6}{|l|}{$\begin{array}{l}\text { Use of needle after others in the } \\
\text { past } 12 \text { months? Yes* }\end{array}$} \\
\hline Once & $5.1(35.3)$ & $9.3(0)$ & $26.1(17.1)$ & $3.7(13.3)$ & $12.6(0)$ \\
\hline Up to 5 times & $3.7(17.5)$ & $0(0)$ & $3.8(14.3)$ & $1.296 .7)$ & $0(0)$ \\
\hline More than 5 times & $4.3(0)$ & $0.5(100)$ & $7.1(31.4)$ & $3.7(6.7)$ & $0(0)$ \\
\hline \multicolumn{6}{|l|}{ Use of needle after others? Yes* } \\
\hline One person & $4.6(26.7)$ & $0(0)$ & $3.0(12.0)$ & $4.1(26.7)$ & $0.7(0)$ \\
\hline Up to 5 people & $3.7(26.7)$ & $0(0)$ & $3.0(8.0)$ & $0.4(0)$ & $0(0)$ \\
\hline More than 5 people & $3.7(0)$ & $0.5(100)$ & $6.6(36.0)$ & $2.4(0)$ & $0(0)$ \\
\hline \multicolumn{6}{|l|}{$\begin{array}{l}\text { Dispensing used needle to others } \\
\text { in past } 12 \text { months? Yes* }\end{array}$} \\
\hline Once & $3.7(6.7)$ & $2.7(0)$ & $17.0(20.0)$ & $2.0(20.0)$ & $32.5(0)$ \\
\hline Up to 5 times & $2.9(26.7)$ & $0.9(0)$ & $3.3(14.3)$ & $1.6(13.3)$ & $0(0)$ \\
\hline More than 5 times & $4.3(0)$ & $0.5(100)$ & $6.6(25.7)$ & $3.7(0)$ & $090)$ \\
\hline \multicolumn{6}{|l|}{$\begin{array}{l}\text { Cleaning needles before re-use in } \\
12 \text { months? Yes* }\end{array}$} \\
\hline Always & $8.9(7.1)$ & $1.6(100)$ & $3.8(18.5)$ & $2.0(13.3)$ & $1.1(0)$ \\
\hline Sometimes & $9.1(28.6)$ & $0(0)$ & $8.8(29.6)$ & $1.6(0)$ & $2.9(0)$ \\
\hline Never & $4.3(42.9)$ & $0(0)$ & $11.3(33.3)$ & $14.6(73.3)$ & $1.1(0)$ \\
\hline \multicolumn{6}{|l|}{$\begin{array}{l}\text { Bleaching needle in the last } 12 \\
\text { months. Yes* }\end{array}$} \\
\hline Always & $1.7(0)$ & $1.6(0)$ & $10.2(16.2)$ & $3.7(0)$ & $24.2(20.0)$ \\
\hline Sometimes & $2.3(0)$ & $5.5(0)$ & $23.6(35.1)$ & $2.4(13.3)$ & $15.2(0)$ \\
\hline Never & $20.3(100)$ & $2.7(100)$ & $30.8(48.6)$ & $19.9(86.7)$ & $24.9(80.0)$ \\
\hline \multicolumn{6}{|l|}{$\begin{array}{l}\text { Equipment cleaning in ways } \\
\text { other than aforementioned } \\
\text { Explain: }\end{array}$} \\
\hline Boiling & 4.9 & 0.5 & 3.6 & 4.9 & 0.4 \\
\hline Disinfectant & 0.9 & 0 & 1.9 & 3.3 & 0 \\
\hline Direct heating & 0 & 0 & 0.5 & 0.4 & 0 \\
\hline Other & 10.6 & 0 & 0.5 & 0.8 & 0 \\
\hline
\end{tabular}

*Percentages in brackets represent HIV positive drug users

For those drug users who knew they were HIV positive $(19.4 \%, \mathrm{n}=276$ out of 1420$)$, at least $47.5 \%$ reported that they had never used a needle after someone else, $52.8 \%$ reported that no one had used a needle before them while $50.7 \%$ reported that no one had used a needle after them within the past 12 months. In Kisumu, there was no sharing or re-use of needles reported but only $30.6 \%$ of the HIV positive drug users reported that they cleaned needles before re-use. Other equipment, apart from needles, was shared by drug users in all centres except in Nakuru and in Kisumu.

Overall, $56.0 \%$ of the drug users in all the centres reported that they were sexually active. In Kisumu, at least three quarters of the drug 
Table 3. Patterns of reported sexual behaviour (\%)

\begin{tabular}{|c|c|c|c|c|c|}
\hline Sexual Behavioural & Mombasa & Malindi & Nairobi & Nakuru & Kisumu \\
\hline $\begin{array}{l}\text { Sexual relationship with } \\
\text { girlfriend/boyfriend? Yes }\end{array}$ & 70.0 & 37.2 & 55.5 & 68.3 & 49.1 \\
\hline Daily & 15.1 & 36.1 & 38.2 & 9.3 & 75.1 \\
\hline Weekly & 33.4 & 14.8 & 28.6 & 37.0 & 12.3 \\
\hline Monthly & 22.3 & 7.1 & 8.5 & 18.0 & 4.3 \\
\hline Yearly & 5.7 & 22.4 & 4.9 & 12.2 & 1.1 \\
\hline \multicolumn{6}{|l|}{$\begin{array}{l}\text { Number of sexual partners } \\
\text { during the last } 12 \text { months }\end{array}$} \\
\hline 1 & 26.3 & 35.5 & 40.9 & 36.6 & 20.9 \\
\hline 2 & 2.6 & 30.1 & 29.9 & 15.9 & 42.6 \\
\hline 3 & 14.3 & 15.8 & 11.5 & 13.4 & 30.7 \\
\hline 4 & 20.3 & 9.8 & 6.6 & 19.5 & 2.2 \\
\hline \multicolumn{6}{|l|}{ Preferred sexual orientation } \\
\hline Man to woman & 86.3 & 50.3 & 66.5 & 86.2 & 39.4 \\
\hline Man to man & 4.0 & 18.0 & 18.4 & 1.2 & 31.8 \\
\hline Woman to woman & 1.7 & 24.6 & 6.0 & 0 & 25.3 \\
\hline Masturbation & 2.3 & 1.1 & 3.0 & 1.6 & 0.4 \\
\hline \multicolumn{6}{|l|}{$\begin{array}{l}\text { Age at first sexual encounter } \\
\text { (years) }\end{array}$} \\
\hline $10-15$ & 48.8 & 21.1 & 40.5 & 41.2 & 41.2 \\
\hline $16-24$ & 62.2 & 46.4 & 42.7 & 43.8 & 29.8 \\
\hline $25-34$ & 0.6 & 24.0 & 1.4 & 2.4 & 13.8 \\
\hline $35+$ & 1.2 & 0 & 2.7 & 3.2 & 0 \\
\hline \multicolumn{6}{|l|}{ Frequency of anal sex } \\
\hline Always & 6.3 & 33.3 & 24.2 & 4.2 & 47.7 \\
\hline Sometimes & 14.6 & 20.8 & 28.6 & 10.6 & 35.7 \\
\hline Rarely & 11.1 & 5.5 & 3.3 & 2.8 & 1.7 \\
\hline \multicolumn{6}{|l|}{ Use of condom during sex* } \\
\hline Never & $32.0(40.0)$ & $26.8(0)$ & $22.5(8.0)$ & $31.7(38.9)$ & $40.4(16.7)$ \\
\hline Sometimes & $39.1(16.0)$ & $39.9(0)$ & $43.1(36.0)$ & $39.4(38.9)$ & $19.1(33.3)$ \\
\hline Always & $25.7(44.0)$ & $13.1(0)$ & $11.0(56.0)$ & $18.7(22.2)$ & $4.0(50.0)$ \\
\hline
\end{tabular}

*Percentages in brackets represent HIV positive drug users

users reported that they had daily sex with a boy/girlfriend. Homosexuality was reported by males and females in all centres except in Nakuru, and was most frequently reported in Kisumu. Sexual activity was initiated as early as at 10 years of age, and majority of the drug users reported having already engaged in sex by the time they were 20 . A very small proportion of the drug users reported condom use during all sexual encounters. Awareness of risky sexual behaviour in relation to HIV/AIDS transmission was not reflected in the sexual practices of the drug users (see Table 3). The percentages of drug users who were HIV positive and who had had sexual encounters without protection ranged from $8.0 \%$ in Nairobi to $40.0 \%$ in Mombasa.
Only $43.1 \%$ overall reported that they always used a condom during a sexual encounter when they were under the influence of drugs, while up to $25.9 \%$ reported that they always had sex without a condom. In this study, $38.2 \%$ of all the respondents $(\mathrm{n}=542)$ knew their HIV status (Nairobi - 11.3\%, Mombasa - 10.6\%, Malindi $-5.6 \%$, Nakuru $-8.4 \%$ and Kisumu $-2.2 \%$ ). It was only in Mombasa that 120 respondents were recruited and tested for HIV and Hepatitis C (41.66\% tested positive for HIV and $60.83 \%$ tested positive for Hepatitis C).

Table 4 presents results on HIV/AIDS awareness and behaviour. A high level of HIV/ AIDS awareness was reported in all the centres (Nairobi - 88.3\%; Malindi - 90.3\%; Kisumu - 
Table 4. HIV/AIDS-related behaviour, practices and effects (\%)

\begin{tabular}{|c|c|c|c|c|c|}
\hline Behavioural & Mombasa & Malindi & Nairobi & Nakuru & Kisumu \\
\hline \multicolumn{6}{|l|}{ Seeking Knowledge about HIV/AIDS } \\
\hline Never & 27.8 & 15.9 & 36.9 & 32.8 & 23.1 \\
\hline Sometimes & 49.9 & 54.7 & 47.4 & 47.1 & 50.0 \\
\hline Always & 22.3 & 29.4 & 15.7 & 20.2 & - \\
\hline \multicolumn{6}{|c|}{$\begin{array}{l}\text { Personal drive to seek for counselling } \\
\text { services }\end{array}$} \\
\hline Never & 43.7 & 31.2 & 56.6 & 36.2 & 73.7 \\
\hline Sometimes & 42.8 & 48.0 & 39.9 & 48.1 & 20.6 \\
\hline Always & 13.5 & 20.8 & 6.4 & 15.7 & 5.7 \\
\hline \multicolumn{6}{|l|}{$\begin{array}{l}\text { Lifelong personal need to test for } \\
\text { HIV/AIDS }\end{array}$} \\
\hline Never & 33.0 & 19.3 & 39.1 & 37.0 & 46.4 \\
\hline Sometimes & 51.4 & 52.1 & 46.1 & 44.1 & 12.1 \\
\hline Always & 15.6 & 28.6 & 14.8 & 18.9 & 41.1 \\
\hline \multicolumn{6}{|l|}{ Spousal feelings for testing } \\
\hline Never & 50.2 & 33.0 & 43.4 & 49.8 & 56.8 \\
\hline Sometimes & 33.1 & 42.6 & 41.5 & 34.8 & 27.3 \\
\hline Always & 16.7 & 24.5 & 15.1 & 15.4 & 15.9 \\
\hline \multicolumn{6}{|l|}{$\begin{array}{l}\text { Effect of HIV/AIDS on sexual } \\
\text { behaviour }\end{array}$} \\
\hline Increased urge for sex & 12.7 & 23.7 & 18.1 & 5.6 & 26.3 \\
\hline More sexual partners & 8.0 & 6.2 & 26.9 & 16.0 & 8.8 \\
\hline Increased abstinence & 36.0 & 21.6 & 30.3 & 43.2 & 40.4 \\
\hline Increased condom use & 43.3 & 48.5 & 24.8 & 35.2 & 24.6 \\
\hline \multicolumn{6}{|l|}{ Spousal reaction to HIV+ status } \\
\hline No change & 27.5 & 24.7 & 23.1 & 14.2 & 16.7 \\
\hline Condom use & 14.6 & 48.2 & 38.7 & 25.2 & 25.6 \\
\hline Abstinence & 35.1 & 1.2 & 17.2 & 18.9 & 20.9 \\
\hline Divorce/separation & 8.8 & 11.8 & 4.6 & 7.9 & 2.3 \\
\hline
\end{tabular}

91.4\%; Mombasa - 92.4\% and Nakuru - 94\%). Overall, there was a high level (91.3\%) of HIV/ AIDS awareness and nearly $90 \%$ of the drug users reported that they were aware that HIV/ AIDS could be transmitted through injecting drugs. However, only $59.7 \%$ were aware about their own HIV/AIDS status with Mombasa reporting an awareness rate of only $44 \%$. The prevalence rates of HIV/AIDS for all centres was reported at 52.3\% for Mombasa, $63.8 \%$ in Malindi, $47.8 \%$ in Nairobi, 35.3\% in Nakuru and $83.9 \%$ in Kisumu. Behaviour related to HIV/AIDS included seeking knowledge, counselling and testing. Even though HIV/ AIDS prevalence was high, up to $46.4 \%$ of the drug users reported that they had never felt a need to go for a test.

The study showed variations in drug use patterns across the five study sites and a significant association between positive HIV status and IDU.

\section{DISCUSSION}

This study is the first one that reflects the socio-demographic characteristics of drug abusing samples from urban and peri-urban areas in Kenya, as past studies have concentrated on school populations. Between 14 and 42 ethnic 
groupings were represented within the study samples. Ethnic diversity was reported at high levels in Mombasa and this was as expected since this is the main port of entry into Kenya and it attracts people from many different parts of the country.

The types of drugs used were similar to those reported in earlier school studies with the exception of parenteral use which is an emerging factor of great magnitude. The 1997 school survey showed only 0.3\% heroin use, $0.3 \%$ Mandrax/amphetamine use and $0.3 \%$ cocaine and Mandrax use (Ndetei et al., 1997). However, the school studies were epidemiological surveys, whereas this study included purposively sampled drug and intravenous drug users from five different centres.

In this study, intravenous use of cocaine and heroin was reported in all the study centres (except in Malindi for cocaine use). In most of the centres, the drug users were current users who were more active at present than in the past one year, and who had used drugs for more than one year. The recorded trend of other members of the nuclear family being drug users (not necessarily abusers) provided a basis for highlighting the importance of involving the nuclear family in drug-related treatment, rehabilitation and educational activities for the abusers.

The pattern of early initiation into sexual behaviour as found in this study has been reported in earlier studies (UNAIDS, 1999). Homosexuality, an emerging phenomenon in Kenya, has been documented for the first time in this study. It is noteworthy that the highest levels of risky sexual behaviour were reported in Kisumu, despite the fact that the respondents were highly knowledgeable about HIV/AIDS. Regional trends of sexual patterns in earlier studies were obscured because data were pooled together. The patterns revealed through this study may explain the regional differences in HIV prevalence statistics (UNAIDS, 1999).

Another phenomenon which has been reported through this study is IDU which was found in all the areas studied. This is a new phenomenon compared with previous published school surveys. Sharing of needles, even by people who knew that they were HIV positive, was found in all the centres suggesting that a positive HIV status and IDU have a significant association in Kenya. On average, only $50 \%$ of the sample knew their HIV status while 34 to $44 \%$ of IDUs knew that they were HIV positive. If it was assumed that the $50 \%$ who did not know their HIV status had an equal chance of being positive for HIV, then it means that in Kenya, at least $68-88 \%$ of IDUs are HIV positive. This is in agreement with findings from Spain (66\%), Myanmar $(66 \%)$, Italy (69\%) and Thailand (80\%) (UNODCP, 2000), reported six years prior to this study. This finding is also corroborated by a serological survey in Mombasa which found that $49.5 \%$ of IDUs were HIV positive, demonstrating a strong association between IDU and HIV.

Very low rates of IDU were reported in Nakuru and Kisumu. Experience in other regions has shown that IDU is a major vector of HIV even in situations where HIV seroprevalence is low. A major concern is that the emerging IDU trend in a high HIV prevalence situation is a recipe for disaster. There is urgent need therefore, for concerted efforts to preempt this from happening through appropriate policy for prevention while at the same time, integrating drug use and in particular IDU, as part of HIV education, prevention, treatment and overall management policy.

\section{ACKNOWLEDGEMENTS}

The Africa Mental Health Foundation (AMHF) provided administrative and logistical support for this study. The AMHF wishes to acknowledge and thank the United Nations Office on Drug and Crime (UNODC) for providing financial support for this study. The authors would like to acknowledge the support of the following in facilitating the process of accessing the study populations and institutions in all the centres: Murad Saad and Olenge Olanya in Mombasa; Aboud Kibwana in Malindi; Joseph Mwai in Nakuru; and Caleb 
Angira in Kisumu. The authors would also like to thank all the participants in the study, Grace Mutevu and Patricia Wekulo of AMHF for their assistance in preparation of the paper.

\section{REFERENCES}

Alary, M. (1999). Overview of HIV among IDUs in Quebec - The SURV-IDU study. Proceedings of the Joint HIV/AIDS and STD Meeting in Calgary, November 1720, 1999. Bureau of HIV/AIDS, STD and TB, LCDC, Health Canada.

Archibald, C. P., Remis, R. S., Farley, J., \& Sutherland, D. (1998). Estimating HIV prevalence and incidence at the national level: Combining direct and indirect methods with Monte-Carlo simulation. XII International Conference on AIDS, Geneva, June-July 1998, (Abst. 43475).

Boys, A., Farrell, M., Taylor, C. et al. (2003). Psychiatric morbidity and substance use in young people aged 13-15 years: Results from the child and adolescent survey of mental health. British Journal of Psychiatry, 182, 509-517.

Centres for Disease Control and Prevention. (1998a). Diagnosis and reporting of HIV and AIDS in states with integrated HIV and AIDS surveillance - United States, January 1994-June 1997,_Morbidity and Mortality Weekly Report, 47 (15), 309314.

Centres for Disease Control and Prevention (1998b). HIV/AIDS Surveillance Report, $10,(2)$ [inclusive page numbers].

Dhadphale, M., Mengech, H. N. R., Syme, D., \& Acuda, S. W. (1982). Drug abuse

among secondary school pupils. A preliminary survey. East Africa Medical Journal, 59, 152-156.

Health Canada. (1997). HIV in Canada: Surveillance of HIV positive test reports for the period 1985-1996. Division of HIV/AIDS Epidemiology and Surveillance, Bureau of HIV/AIDS, STD and TB, Centre for Infectious Disease Prevention and Control: Health Canada.
Health Canada. (2000). HIV and AIDS in Canada: Surveillance Report to December 31, 1999. Division of HIV/AIDS Epidemiology and Surveillance. Bureau of HIV/AIDS, STD and TB, LCDC, HPB, Health Canada.

Joint United Nations Programme on HIV/AIDS. (1999). 1999 Report on the global AIDS epidemic. Geneva: UNAIDS.

Kuria, W. (1996). Drug abuse among urban as compared to rural secondary school

students in Kenya. East Africa Medical Journal, 73 (5), 339.

Lamothe, F. (1999). Overview of HIV among IDUs in Quebec - The St. Luc Cohort Study on IDUs. Proceedings of the Joint HIV/AIDS and STD Meeting, Calgary, November 17-20, 1999. Bureau of HIV/AIDS, STD and TB, LCDC, Health Canada.

Millson, P. E., Myers, T., Calzavara, L., Major, C., Fearon, M., Rea, E., \& Wallace, E. (2000). Inventory of HIV Incidencel Prevalence Studies in Canada, April 2000. Produced by the Division of HIV Epidemiology, Bureau of HIV/AIDS, STD and TB, LCDC, Health Canada.

The National Agency for the Campaign Against Drug Abuse (2004). Youth in Peril:

Alcohol and Drug Abuse in Kenya. Nairobi: NACADA.

Ndetei, D.M. (2004). A study on the assessment of the linkages between drug abuse,

injecting drug abuse and HIV/AIDS in Kenya: A rapid situation assessment (RSA) 2004. Nairobi: United Nations Office on Drugs and Crime (UNODC).

Ndetei, D. M., Kathuku, D. M., \& Othieno, C. J. et al (1997). Economic-social-

political aspects of illicit drug use in Kenya. Department of Psychiatry: University of Nairobi. A UNDCP funded project

Patrick, D. M., Schechter, M. T., Strathdee, S. A., Cornelisse, P. G. A., Rekart, M. L., Cook, D., Montaner, J. S. G., \& O’Shaughnessy, M. V. (1998). HIV Incidence in Vancouver IDUs follows a predictable decline. Seventh Annual Canadian Conference on HIV/ AIDS, Quebec, 1998. Canadian Journal of Infectious Diseases, 9 (Suppl. A), 270P. 
Smart, R. G., Hughes, P. H., \& Johnson, L.D. et al. (1980). A methodology for student

drug-use surveys (WHO Offset Publication No. 50). Geneva: World Health Organisation.

Tannenbaum, T. (1999). Overview of HIV among IDUs in Quebec - The HIV and AIDS surveillance program. Proceedings of the Joint HIV/AIDS and STD Meeting, Calgary, November 17-20, 1999. Bureau of HIV/AIDS, STD and TB, LCDC, Health Canada.

Tyndall, M. (1999). Overview of HIV among IDUs in B.C. - VIDUS. Proceedings of the Joint HIV/AIDS and STD Meeting, Calgary, November 17-20, 1999. Bureau of HIV/AIDS, STD and TB, LCDC, Health Canada.

United Nations Office for Drug Control and Crime Prevention. (2000). 2000 World drug report. Vienna: UNODCP
Wallace, E. (1999). Overview of HIV among IDUs in Ontario - The HIV and AIDS

surveillance program. Proceedings of the Joint HIV/AIDS and STD Meeting, Calgary, November 17-20, 1999. Bureau of HIV/ AIDS, STD and TB, LCDC,

Health Canada.

Weekly Epidemiological Record. (1995). Provisional working estimates of adult HIV

prevalence as of end of 1994 by country. 70 (50), 355-356.

www.HIVdent.org

Yambo, M., \& Acuda, S.W. (1983). Epidemiology of drug use and abuse: Final

report of a pilot study of Nairobi city and Kyaume sub-location, Kenya. Nairobi: Department of Psychiatry, University of Nairobi. 